\title{
EFEITO DE RODAS COMPACTADORAS SUBMETIDAS A CARGAS VERTICAIS EM PROFUNDIDADES DE SEMEADURA SOBRE O DESENVOLVIMENTO DO MILHO ${ }^{1}$
}

\author{
ROUVERSON P. DA SILVA ${ }^{2}$, JOSÉ E. CORÁ ${ }^{3}$, ALBERTO CARVALHO FILHO 4 , \\ AFONSO LOPES ${ }^{2}$, CARLOS E. A. FURLANI ${ }^{2}$
}

\begin{abstract}
RESUMO: O sucesso de implantação de uma cultura pode ser garantido por uma semeadura bem realizada, e as rodas compactadoras utilizadas nessa operação devem ser capazes de melhorar o contato solo-semente para promover boa emergência das plântulas. O objetivo deste trabalho foi estudar a influência de três modelos de rodas compactadoras, três profundidades de semeadura e três níveis de carga sobre a roda compactadora na germinação e no desenvolvimento da cultura do milho, em uma pista de ensaios projetada para essa finalidade, no município de Uberaba - MG, em Latossolo Vermelho distrófico, textura média. $\mathrm{O}$ delineamento experimental utilizado foi $\mathrm{o}$ de parcelas subsubdivididas, com 27 tratamentos e quatro repetições. Os resultados obtidos evidenciaram que a profundidade de semeadura foi o fator que mais afetou o desenvolvimento vegetativo da cultura do milho no estádio 2, enquanto no estádio 4 nenhum dos fatores afetou as medidas de desenvolvimento da cultura.
\end{abstract}

PALAVRAS-CHAVE: canal de solo, semeadura, emergência.

\section{EFFECT OF PRESS WHEELS SUBMITTED TO VERTICAL LOADS IN DEPTHS OF SOWING ON CORN CROP DEVELOPMENT}

SUMMARY: The success of the establishment of a crop depend on several factors and the seeders press wheels should be capable to improve the contact soil-seed in order to promote good seed germination. The present work had as objective to study the influence of three models of press wheel, three depths of sowing and three load levels on the press wheel on the germination and development of the corn grow, in a projected sowing assay lane for this purpose. The experiment was carried out at municipal district of Uberaba - MG, Brazil, in a split plot array, with 27 treatments and four replications, used to evaluate agronomic characteristics of the corn crop. The results evidenced that the depth of sowing was the factor that more affected the vegetative development of the corn crop in the stadium 2, and none of the evaluated characteristics in the stadium 4 had significant differences in the measures of the corn development.

KEYWORDS: soil bin, sowing, emergence.

\section{INTRODUÇÃO}

As rodas compactadoras têm a função de melhorar o contato entre o solo e a semente por meio da aplicação de uma pressão lateral e sobre o sulco de semeadura, provocando leve compactação e deixando o solo diretamente sobre as sementes, solto o suficiente para facilitar a emergência das plântulas. Além dessa pressão, outro fator a ser considerado na operação de semeadura é a profundidade de deposição das sementes, que é condicionada pela temperatura, teor de água e tipo de

\footnotetext{
${ }^{1}$ Parte da Tese de Doutorado do primeiro autor junto à FCAV/UNESP.

${ }^{2}$ Prof. Dr., Departamento de Engenharia Rural, FCAV/UNESP, Jaboticabal - SP, Fone: (0XX16) 3209.2637, Ramal 232 e-mail: rouverson@fcav.unesp.br.

3 Prof. Dr., Departamento de Solos e Adubos, FCAV/UNESP, Jaboticabal - SP.

${ }^{4}$ Doutorando em Ciência do Solo, FCAV/UNESP, Professor das Faculdades Associadas de Uberaba.

Recebido pelo Conselho Editorial em: 2-7-2003

Aprovado pelo Conselho Editorial em: 3-6-2004
}

Eng. Agríc., Jaboticabal, v.24, n.2, p.396-404, maio/ago. 2004 
solo, dentre outros fatores. A profundidade de deposição da semente deve ser tal que permita bom contato com o solo úmido, resultando em boa germinação.

As rodas compactadoras têm a função de aumentar o contato das sementes com o solo para melhorar a absorção de água, garantindo melhor germinação (PACHECO, 1994). Vários autores têm estudado a relação máquina-solo-planta em ensaios de semeadura, utilizando rodas compactadoras cilíndricas metálicas. FURLANI et al. (2001), combinando três profundidades de semeadura da cultura do milho com quatro níveis de compactação do solo sobre as sementes, não encontraram influência desses fatores sobre o número médio de dias para emergência das plântulas de milho. Por outro lado, a resistência mecânica do solo à penetração aumentou com a utilização de maiores cargas sobre a roda compactadora. ORTOLANI et al. (1986), estudando a emergência e o desenvolvimento do sorgo granífero verificaram que uma profundidade de semeadura igual a $4 \mathrm{~cm}$ e uma carga de $200 \mathrm{~N}$, sobre uma roda compactadora cilíndrica, proporcionaram melhores condições de emergência e desenvolvimento vegetativo das plantas, antecipando-se aos demais tratamentos. COAN (1996), estudando o efeito da profundidade de semeadura e da compactação do solo sobre a semente no comportamento da aveia-preta, verificou que a emergência, o desenvolvimento e a produção de matéria seca acumulada na parte aérea das plantas foram maiores para a combinação da profundidade de $3 \mathrm{~cm}$ e aplicação de carga de $100 \mathrm{~N}$, enquanto a semeadura na profundidade de $1 \mathrm{~cm}$ sem compactação prejudicou o estande e o crescimento inicial das plantas. A carga de $150 \mathrm{~N}$ foi prejudicial às plantas, alterando o comportamento físico do solo, avaliado por meio da densidade do solo e do índice de cone.

STEFANUTTI (1979), trabalhando com um único modelo de roda, mudando apenas as cargas de compactação, constatou a alteração de valores para densidade e temperatura do solo em relação à profundidade, comprovando que a modificação do comportamento físico proporcionado à semente e plântulas é provocada apenas pela regulagem de carga da roda compactadora sobre o solo.

HUMMEL et al. (1981), trabalhando com diferentes tipos de rodas compactadoras na semeadura de soja, afirmaram que o desenho e a operação da roda compactadora apresentaram considerável influência, benéfica ou não, sobre o ambiente do solo em torno da semente, e que seu efeito depende do nível de pressão e desenho da roda, do teor de água e do tipo do solo e das condições climáticas no período entre a semeadura e a emergência.

SILVA (1990) realizou um estudo para verificar a influência de quatro diferentes modelos de rodas compactadoras sobre alguns parâmetros físicos do solo e também sobre o desenvolvimento das plantas na cultura do feijão, utilizando três níveis de compactação. Seus resultados mostraram que existe um comportamento distinto entre os tipos de rodas e cargas de compactação em relação ao desenvolvimento de plantas, à produção de grãos e à alteração nas características físicas do solo.

\section{MATERIAL E MÉTODOS}

O trabalho foi desenvolvido na Área Experimental da FAZU - Faculdades Associadas de Uberaba, localizada no município de Uberaba - MG, cujas coordenadas geográficas são latitude $19^{\circ} 44^{\prime} 13$ ' S, longitude 4757'27' W e altitude de $780 \mathrm{~m}$.

O solo da área experimental é classificado como Latossolo Vermelho distrófico, textura média (EMBRAPA, 1999), e a pista é constituída de sete canais de solo nivelados, delimitados por trilhos, sobre os quais desliza um trole acionado por motor elétrico. A pista para ensaios de semeadura da FAZU - Faculdades Associadas de Uberaba, foi construída tomando-se como modelo uma pista semelhante existente na FCAV/UNESP, em Jaboticabal - SP, projetada por STEFANUTTI (1979).

Para a realização dos ensaios, foram escolhidos três modelos de rodas (Figura 1), classificadas de acordo com a ASAE (1995) em: 
- Roda 1: roda duplo-angulada, constituída por duas rodas cilíndricas em "V", revestidas com borracha maciça, normalmente usada para semeadura direta;

- Roda 2: roda convexa larga, revestida com borracha deformável, tipo câmara-de-ar, e

- Roda 3: roda dupla com nervura simples, constituída por duas rodas cilíndricas, revestidas com borracha maciça, com nervura central; por possuir eixos inclinados, essa roda acompanha a forma de um "V".
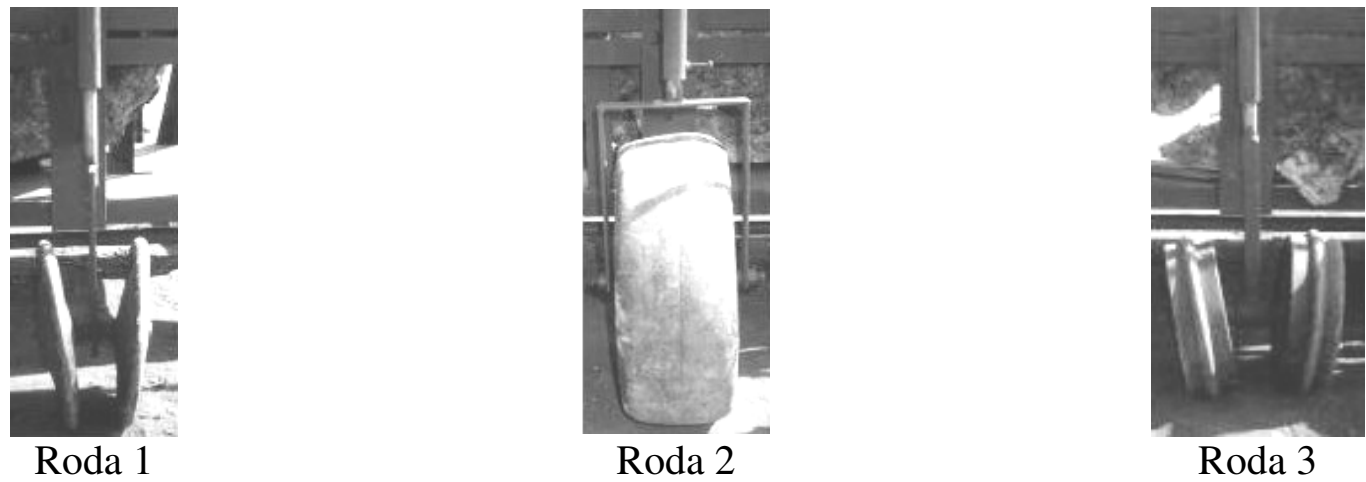

FIGURA 1. Modelos das rodas compactadoras.

Os tratamentos foram constituídos por meio da combinação de três modelos de rodas compactadoras (R1, R2 e R3) com três níveis de carga $(\mathrm{C} 1=50, \mathrm{C} 2=100$ e $\mathrm{C} 3=150 \mathrm{~N})$ e três profundidades de semeadura $(\mathrm{P} 1=3, \mathrm{P} 2=5$ e $\mathrm{P} 3=7 \mathrm{~cm})$, totalizando 27 tratamentos com quatro repetições, em delineamento de parcelas subsubdivididas (Figura 2).

Foi utilizado milho híbrido simples, Aventis A-2288, superprecoce, com pureza mínima de 98\% e germinação mínima de $85 \%$. Esse híbrido possui características adequadas para a exploração na Zona Macroagroecológica do Cerrado do Brasil Central (MONTEIRO et al., 1992).

A aplicação dos tratamentos obedeceu à seguinte metodologia:

- O comprimento das parcelas foi estabelecido em $2 \mathrm{~m}$ em toda a largura da pista, com três fileiras espaçadas de $0,75 \mathrm{~m}$, nas quais foram depositadas duas sementes a cada $20 \mathrm{~cm}$, resultando em 66.667 plantas por hectare após o desbaste;

- A semeadura foi realizada manualmente, abrindo-se pequenas covas com o auxílio de cilindros de madeira posicionados sobre uma régua perfurada, no espaçamento desejado. Os cilindros, com comprimento igual às profundidades almejadas e diâmetro de $15 \mathrm{~mm}$, foram comprimidos contra $\mathrm{o}$ solo até encostar na régua;

- Logo após a semeadura, as rodas foram fixadas ao suporte e esse à face vertical do trole portaferramentas, sendo então posicionadas de modo que a linha de semeadura ficasse no centro do plano vertical das rodas compactadoras;

- As rodas foram posicionadas no centro das entrefaixas e as cargas estáticas correspondentes a cada tratamento foram colocadas sobre o eixo vertical das rodas, evitando-se impactos sobre o solo, e

- O trole foi acionado até o início da próxima entrefaixa, quando as cargas foram então alteradas de acordo com o tratamento a ser aplicado. Esse procedimento foi repetido até o fim do canal, quando então o trole foi mudado de trilho por meio de um chassi de transferência. 


\begin{tabular}{|c|c|c|c|c|c|c|c|c|}
\hline R1P3C3 & R1P3C2 & R1P3C1 & R1P1C1 & R1P1C3 & R1P1C1 & $\mathrm{R} 1 \mathrm{P} 2 \mathrm{C} 3$ & $\mathrm{R} 1 \mathrm{P} 2 \mathrm{C} 1$ & $\mathrm{R} 1 \mathrm{P} 2 \mathrm{C} 2$ \\
\hline R3P3C2 & R3P3C1 & R3P3C3 & R3P1C2 & R3P1C1 & R3P1C3 & $\mathrm{R} 3 \mathrm{P} 2 \mathrm{C} 3$ & $\mathrm{R} 3 \mathrm{P} 2 \mathrm{C} 2$ & $\mathrm{R} 3 \mathrm{P} 2 \mathrm{C} 1$ \\
\hline $\mathrm{R} 2 \mathrm{P} 2 \mathrm{C} 3$ & $\mathrm{R} 2 \mathrm{P} 2 \mathrm{C} 1$ & $\mathrm{R} 2 \mathrm{P} 2 \mathrm{C} 2$ & $\mathrm{R} 2 \mathrm{P} 3 \mathrm{C} 3$ & $\mathrm{R} 2 \mathrm{P} 3 \mathrm{C} 2$ & $\mathrm{R} 2 \mathrm{P} 3 \mathrm{C} 1$ & $\mathrm{R} 2 \mathrm{P} 1 \mathrm{C} 1$ & $\mathrm{R} 2 \mathrm{P} 1 \mathrm{C} 2$ & $\mathrm{R} 2 \mathrm{P} 1 \mathrm{C} 3$ \\
\hline $\mathrm{R} 2 \mathrm{P} 1 \mathrm{C} 1$ & $\mathrm{R} 2 \mathrm{P} 1 \mathrm{C} 3$ & $\mathrm{R} 2 \mathrm{P} 1 \mathrm{C} 2$ & $\mathrm{R} 2 \mathrm{P} 3 \mathrm{C} 3$ & $\mathrm{R} 2 \mathrm{P} 3 \mathrm{C} 1$ & $\mathrm{R} 2 \mathrm{P} 3 \mathrm{C} 2$ & $\mathrm{R} 2 \mathrm{P} 2 \mathrm{C} 1$ & $\mathrm{R} 2 \mathrm{P} 2 \mathrm{C} 2$ & $\mathrm{R} 2 \mathrm{P} 2 \mathrm{C} 3$ \\
\hline R1P1C1 & R1P1C2 & R1P1C3 & $\mathrm{R} 1 \mathrm{P} 2 \mathrm{C} 3$ & $\mathrm{R} 1 \mathrm{P} 2 \mathrm{C} 2$ & $\mathrm{R} 1 \mathrm{P} 2 \mathrm{C} 1$ & $\mathrm{R} 1 \mathrm{P} 3 \mathrm{C} 2$ & $\mathrm{R} 1 \mathrm{P} 3 \mathrm{C} 1$ & $\mathrm{R} 1 \mathrm{P} 3 \mathrm{C} 3$ \\
\hline $\mathrm{R} 3 \mathrm{P} 2 \mathrm{C} 2$ & R3P2C1 & R3P2C3 & $\mathrm{R} 3 \mathrm{P} 3 \mathrm{C} 1$ & R3P3C3 & $\mathrm{R} 3 \mathrm{P} 3 \mathrm{C} 2$ & R3P1C1 & $\mathrm{R} 3 \mathrm{P} 1 \mathrm{C} 2$ & R3P1C3 \\
\hline R3P1C1 & R3P1C3 & $\mathrm{R} 3 \mathrm{P} 1 \mathrm{C} 2$ & R3P3C1 & R3P3C3 & $\mathrm{R} 3 \mathrm{P} 3 \mathrm{C} 2$ & $\mathrm{R} 3 \mathrm{P} 2 \mathrm{C} 2$ & $\mathrm{R} 3 \mathrm{P} 2 \mathrm{C} 1$ & $\mathrm{R} 3 \mathrm{P} 2 \mathrm{C} 3$ \\
\hline R1P1C3 & R1P1C2 & $\mathrm{R} 1 \mathrm{P} 1 \mathrm{C} 1$ & R1P3C3 & R1P3C2 & $\mathrm{R} 1 \mathrm{P} 3 \mathrm{C} 1$ & $\mathrm{R} 1 \mathrm{P} 2 \mathrm{C} 1$ & R1P2C3 & $\mathrm{R} 1 \mathrm{P} 2 \mathrm{C} 2$ \\
\hline $\mathrm{R} 2 \mathrm{P} 1 \mathrm{C} 1$ & R2P1C3 & $\mathrm{R} 2 \mathrm{P} 1 \mathrm{C} 2$ & $\mathrm{R} 2 \mathrm{P} 3 \mathrm{C} 3$ & $\mathrm{R} 2 \mathrm{P} 3 \mathrm{C} 1$ & $\mathrm{R} 2 \mathrm{P} 3 \mathrm{C} 2$ & $\mathrm{R} 2 \mathrm{P} 2 \mathrm{C} 3$ & $\mathrm{R} 2 \mathrm{P} 2 \mathrm{C} 2$ & $\mathrm{R} 2 \mathrm{P} 2 \mathrm{C} 1$ \\
\hline R1P1C2 & $\mathrm{R} 1 \mathrm{P} 1 \mathrm{C} 1$ & R1P1C3 & R1P2C3 & $\mathrm{R} 1 \mathrm{P} 2 \mathrm{C} 1$ & $\mathrm{R} 1 \mathrm{P} 2 \mathrm{C} 2$ & $\mathrm{R} 1 \mathrm{P} 3 \mathrm{C} 1$ & $\mathrm{R} 1 \mathrm{P} 3 \mathrm{C} 2$ & R1P3C3 \\
\hline $\mathrm{R} 2 \mathrm{P} 2 \mathrm{C} 1$ & $\mathrm{R} 2 \mathrm{P} 2 \mathrm{C} 2$ & $\mathrm{R} 2 \mathrm{P} 2 \mathrm{C} 3$ & $\mathrm{R} 2 \mathrm{P} 3 \mathrm{C} 3$ & $\mathrm{R} 2 \mathrm{P} 3 \mathrm{C} 2$ & $\mathrm{R} 2 \mathrm{P} 3 \mathrm{C} 1$ & $\mathrm{R} 2 \mathrm{P} 1 \mathrm{C} 1$ & $\mathrm{R} 2 \mathrm{P} 1 \mathrm{C} 3$ & $\mathrm{R} 2 \mathrm{P} 1 \mathrm{C} 2$ \\
\hline R3P2C3 & R3P2C2 & R3P2C1 & R3P1C3 & R3P1C1 & $\mathrm{R} 3 \mathrm{P} 1 \mathrm{C} 2$ & R3P3C2 & $\mathrm{R} 3 \mathrm{P} 3 \mathrm{C} 2$ & $\mathrm{R} 3 \mathrm{P} 3 \mathrm{C} 1$ \\
\hline
\end{tabular}

FIGURA 2. Disposição dos tratamentos na área experimental.

Após a semeadura, realizou-se a irrigação de todas as parcelas. Durante a fase de desenvolvimento da cultura, foram realizadas irrigações a cada três dias, com aplicação de uma lâmina de $5 \mathrm{~mm}$.

O desbaste foi efetuado 21 dias após a semeadura, deixando 14 plantas por linha; na mesma data, realizou-se adubação em cobertura, com uréia granulada, na dosagem de $100 \mathrm{~kg} \mathrm{ha}{ }^{-1}$, aplicada manualmente em sulco raso, no lado direito da planta, seguida de irrigação.

As avaliações da cultura foram realizadas em duas etapas distintas, seguindo a metodologia apresentada por BENINCASA (1988). A primeira etapa ocorreu durante a fase de desenvolvimento inicial da cultura, quando se avaliou a emergência das plântulas. Em um segundo momento, que compreendeu todo o período de crescimento das plantas, determinaram-se a massa de matéria seca, a altura das plantas e a altura de inserção da primeira espiga. Para a avaliação da emergência, procedeuse à contagem diária de todas as plântulas emergidas em cada tratamento, até que o número total se tornasse repetitivo em cada tratamento, por três dias consecutivos. Cada plântula foi considerada emergida a partir do instante em que a mesma rompeu o solo e pôde ser vista a olho nu, de algum ângulo qualquer. A partir dessas contagens, expressou-se o número médio de dias para a emergência das plântulas, de acordo com a eq.(1), proposta por EDMOND \& DRAPALA (1958), citados por SIQUEIRA (1999).

$$
M=\frac{\left[\left(N_{1} \cdot G_{1}\right)+\left(N_{2} \cdot G_{2}\right)+\ldots+\left(N_{n} \cdot G_{n}\right)\right]}{\left(G_{1}+G_{2}+\ldots+G_{n}\right)}
$$

em que,

M - número médio de dias para a emergência das plântulas de milho;

$\mathrm{N}_{1}$ - número de dias decorridos entre a semeadura e a primeira contagem de plântulas;

$\mathrm{G}_{1}$ - número de plântulas emergidas na primeira contagem;

$\mathrm{N}_{2}$ - número de dias decorridos entre a semeadura e a segunda contagem de plântulas;

$\mathrm{G}_{2}$ - número de plântulas emergidas entre a primeira e a segunda contagem;

$\mathrm{N}_{\mathrm{n}}$ - número de dias decorridos entre a semeadura e a última contagem de plântulas, e

$\mathrm{G}_{\mathrm{n}}$ - número de plântulas emergidas entre a penúltima e a última contagem. 
A massa seca total da parte aérea das plantas foi medida aos 21 dias após a semeadura, utilizando-se de cinco plantas de cada subsubparcela, que foram acondicionadas em sacos de papel e levadas à estufa a $70^{\circ} \mathrm{C}$, até massa constante.

As avaliações referentes à altura de plantas foram realizadas semanalmente, iniciando-se sete dias após o desbaste, com auxílio de uma régua graduada em centímetros, nas três plantas centrais de cada tratamento, medindo-se a altura do solo até o ponto de inflexão da folha mais alta da planta.

A altura de inserção da primeira espiga foi determinada aos 100 dias após a semeadura, por meio da distância entre o solo e o internódio de inserção da primeira espiga, com o auxílio de uma trena de aço, nas três plantas centrais de cada tratamento. Os resultados obtidos foram tabulados e submetidos à análise de variância, utilizando-se do programa SANEST. Quando o valor do teste F se mostrou significativo a $5 \%$ de probabilidade, aplicou-se o teste de Tukey para comparação entre as médias. Para as interações significativas a 5\% de probabilidade, realizou-se o desdobramento da análise de variância, considerando-se os fatores profundidade e carga isoladamente.

\section{RESULTADOS E DISCUSSÃO}

Com relação ao número médio de dias para a emergência das plântulas, pôde-se observar que, dentre todos os fatores e interações estudados, apenas a profundidade de semeadura afetou de forma significativa a emergência do milho (Tabela 1). As sementes colocadas a profundidades de $3 \mathrm{~cm}(\mathrm{P} 1)$ necessitaram de menos dias para emergência e apresentaram maior porcentagem de emergência do que aquelas colocadas em profundidades de $5(\mathrm{P} 2)$ e $7 \mathrm{~cm}(\mathrm{P} 3)$. Do total de sementes colocadas à profundidade de $3 \mathrm{~cm}, 49,5 \%$ emergiram aos quatro dias após a semeadura, enquanto, na mesma data, somente $19 \%$ e $13 \%$ das sementes colocadas às profundidades de 5 e $7 \mathrm{~cm}$, respectivamente, atingiram a emergência.

Esses resultados concordam com os de RAMOS (2001), que concluiu que a profundidade afetou de forma significativa a emergência do milho, e com a afirmação de FANCELLI \& DOURADO NETO (2000), de que uma semeadura muito profunda atua como fator de estresse para a semente, levando à emergência tardia das plântulas. Como o solo foi mantido sob irrigação durante a condução do experimento, o fato de o nível de carga e suas interações não terem afetado a emergência das plântulas de milho, pode ser explicado pelo alto teor de água do solo. JOHNSON \& BUCHELE (1961) afirmaram que um solo seco e compactado oferece resistência considerável na emergência das plântulas de milho, enquanto JOHNSON \& HENRY (1964) observaram que a carga do solo atrasou ou impediu a emergência do milho, exceto para o caso de a zona compactada ser mantida com alto teor de água no solo, o que diminuiria a força de resistência do mesmo.

Para a massa de matéria seca, os resultados obtidos revelam que não houve diferença significativa para os fatores analisados e suas interações. Dessa forma, pode-se assegurar que, no momento do desbaste, todos os tratamentos alcançaram produções de matéria seca estatisticamente semelhantes (Tabela 1). MINAMI (s.d.), citado por TILMANN et al. (1994), afirmou que, em semeaduras mais rasas, normalmente, as sementes ficam mais sujeitas às variações ambientais, podendo originar plântulas fracas e pequenas. Neste trabalho, as sementes colocadas à profundidade de $3 \mathrm{~cm}$ (P1) apresentaram as maiores porcentagens de germinação, mas os resultados da avaliação da massa de matéria seca indicam que essas sementes não resultaram em plântulas mais fracas. 
TABELA 1. Síntese da análise de variância e do teste de médias para os valores do número de dias para emergência das plântulas de milho (NMDPE) e da massa de matéria seca (MS).

\begin{tabular}{lcc}
\hline \multicolumn{1}{c}{ Fator } & NMDPE (dias) & MS (g planta $\left.{ }^{-1}\right)$ \\
\hline Roda 1 & 8,9 & 7,5 \\
Roda 2 & 8,8 & 7,5 \\
Roda 3 & 8,8 & 7,1 \\
\hline Profundidade 1 & $8,6 \mathrm{c}$ & 7,5 \\
Profundidade 2 & $8,8 \mathrm{~b}$ & 7,4 \\
Profundidade 3 & $9,0 \mathrm{a}$ & 7,2 \\
\hline Carga 1 & 8,9 & 7,5 \\
Carga 2 & 8,8 & 7,5 \\
Carga 3 & 8,8 & 7,1 \\
\hline Rodas (R) & $0,36 \mathrm{NS}$ & $3,63 \mathrm{NS}$ \\
Profundidades (P) & $39,23 *$ & $0,24 \mathrm{NS}$ \\
R x P & $1,12 \mathrm{NS}$ & $0,52 \mathrm{NS}$ \\
Carga & $1,37 \mathrm{NS}$ & $0,93 \mathrm{NS}$ \\
R x C & $0,99 \mathrm{NS}$ & $1,36 \mathrm{NS}$ \\
P x C & $0,96 \mathrm{NS}$ & $0,36 \mathrm{NS}$ \\
R x P x C & $0,54 \mathrm{NS}$ & $0,94 \mathrm{NS}$ \\
\hline C.V. Roda (\%) & 1,26 & 3,65 \\
C.V. Profundidade (\%) & 1,34 & 11,23 \\
C.V. Carga (\%) & 2,46 & 17,32 \\
\hline
\end{tabular}

* significativo a 5\% de probabilidade; NS: não significativo.

O desenvolvimento das alturas das plantas em função dos modelos de rodas compactadoras, da profundidade de semeadura e do nível de carga sobre a roda compactadora apresentou pequena diferença entre as alturas das plantas nos diversos estádios, em todos os tratamentos.

VIÉGAS \& PEETEN (1987) e ROSOLEM (1995) afirmam que, à medida que a planta se aproxima do estádio reprodutivo, se o ambiente for propício, a tendência é de todas as plantas se igualarem, pois a conformação final da planta é determinada geneticamente. Isso fica evidente ao se observar que a profundidade de semeadura e a interação entre profundidade de semeadura e carga (P x C) alteraram significativamente a altura média das plantas no estádio 2. No estádio 3, a altura média das plantas foi alterada pela interação entre profundidade e carga (P x C), enquanto, no estádio 4, nenhum dos fatores ou interação entre eles proporcionou diferenças significativas na altura das plantas (Tabela 2).

Verificou-se, durante o estádio 2, que as profundidades de semeaduras mais superficiais favoreceram o crescimento das plantas, tendência essa também observada para o efeito da profundidade dentro do nível de carga 2 (Tabela 3), em que a profundidade de $3 \mathrm{~cm}$ (P1) apresentou maior altura das plantas do que a profundidade de $7 \mathrm{~cm}$ (P3). Dentro dos níveis de carga 1 e 3, os efeitos da profundidade não apresentaram diferenças significativas (Tabela 3).

No estádio 3, verificou-se que as interações de profundidade dentro das cargas 2 e 3 alteraram significativamente as médias das alturas das plantas (Tabela 3). As maiores médias para essa variável foram encontradas para as profundidades de $7 \mathrm{~cm}(\mathrm{P} 3)$ e $3 \mathrm{~cm}(\mathrm{P} 1)$, dentro do nível de carga $3(150 \mathrm{~N})$, e para as profundidades de $3 \mathrm{~cm}(\mathrm{P} 1)$ e $5 \mathrm{~cm}(\mathrm{P} 2)$, dentro do nível de carga $2(100 \mathrm{~N})$.

$\mathrm{Na}$ avaliação do segundo estádio, as profundidades mais superficiais (3 e $5 \mathrm{~cm}$ ) levaram a um desenvolvimento de plantas com alturas semelhantes, e a semeadura mais profunda $(7 \mathrm{~cm})$ levou a um menor crescimento em altura. Esse resultado concorda com a afirmação de FANCELLI \& DOURADO 
NETO (2000) de que as plântulas provenientes de semeaduras mais profundas emergem tardiamente. Porém, durante o desenvolvimento da planta, a maior profundidade de semeadura não afetou de forma significativa a altura das plantas e, no estádio 4, a altura das plantas foi estatisticamente igual. Resultados semelhantes também foram obtidos por RAMOS (2001).

TABELA 2. Síntese da análise de variância e do teste de médias para os valores médios de altura das plantas.

\begin{tabular}{lcccc}
\hline \multirow{2}{*}{ Fator } & \multicolumn{3}{c}{ Altura das Plantas (cm) } & \multirow{2}{*}{ AIPE (cm) } \\
\cline { 2 - 4 } & Estádio 2 & Estádio 3 & Estádio 4 & \\
\hline Roda 1 & 52,6 & 80,6 & 109,0 & 46,8 \\
Roda 2 & 52,2 & 78,8 & 105,5 & 46,8 \\
Roda 3 & 53,0 & 81,9 & 110,8 & 48,3 \\
\hline Profundidade 1 & $54,8 \mathrm{a}$ & 82,2 & 108,1 & 46,7 \\
Profundidade 2 & $52,8 \mathrm{ab}$ & 79,4 & 107,9 & 48,4 \\
Profundidade 3 & $50,2 \mathrm{~b}$ & 79,7 & 109,3 & 45,8 \\
\hline Carga 1 & 52,4 & 79,1 & 106,0 & 46,9 \\
Carga 2 & 52,6 & 81,0 & 108,8 & 47,2 \\
Carga 3 & 52,4 & 81,1 & 110,4 & 47,8 \\
\hline Rodas (R) & $0,10 \mathrm{NS}$ & $0,67 \mathrm{NS}$ & $1,40 \mathrm{NS}$ & $0,38 \mathrm{NS}$ \\
Profundidades (P) & $8,13 *$ & $0,95 \mathrm{NS}$ & $0,12 \mathrm{NS}$ & $2,59 \mathrm{NS}$ \\
R x P & $2,28 \mathrm{NS}$ & $0,66 \mathrm{NS}$ & $2,17 \mathrm{NS}$ & $0,68 \mathrm{NS}$ \\
Carga & $0,03 \mathrm{NS}$ & $0,80 \mathrm{NS}$ & $1,23 \mathrm{NS}$ & $0,49 \mathrm{NS}$ \\
R x C & $1,05 \mathrm{NS}$ & $0,55 \mathrm{NS}$ & $0,54 \mathrm{NS}$ & $1,58 \mathrm{NS}$ \\
P x C & $3,24 *$ & $4,75 *$ & $1,59 \mathrm{NS}$ & $1,42 \mathrm{NS}$ \\
R x P x C & $0,87 \mathrm{NS}$ & $1,20 \mathrm{NS}$ & $0,82 \mathrm{NS}$ & $1,13 \mathrm{NS}$ \\
\hline C.V. Roda (\%) & 5,28 & 4,76 & 4,19 & 6,16 \\
C.V. Profundidade (\%) & 5,23 & 6,72 & 7,03 & 7,28 \\
C.V. Carga (\%) & 10,42 & 9,44 & 11,07 & 7,93 \\
\hline
\end{tabular}

* significativo a $5 \%$ de probabilidade; NS: não significativo.

TABELA 3. Valores médios de altura das plantas, nos estádios 2 e 3, aos 28 e 42 dias após a emergência, para o estudo do efeito do fator profundidade dentro do fator carga.

\begin{tabular}{cccc}
\hline \multirow{2}{*}{ Efeito } & \multirow{2}{*}{ Fator } & \multicolumn{2}{c}{ Altura $(\mathrm{cm})$} \\
\cline { 3 - 4 } & & Estádio 2 & Estádio 3 \\
\hline \multirow{2}{*}{ Profundidade dentro de Carga 1 } & P1 & 53,1 & 77,1 \\
& P2 & 55,2 & 83,1 \\
& P3 & 50,0 & 77,2 \\
\hline \multirow{2}{*}{ Profundidade dentro de Carga 2 } & P1 & $57,4 \mathrm{a}$ & $86,0 \mathrm{a}$ \\
& P2 & $52,5 \mathrm{ab}$ & $79,5 \mathrm{ab}$ \\
& P3 & $48,0 \mathrm{~b}$ & $77,6 \mathrm{~b}$ \\
\hline \multirow{2}{*}{ Profundidade dentro de Carga 3 } & P1 & 53,8 & $83,4 \mathrm{a}$ \\
& P2 & 50,7 & $75,8 \mathrm{~b}$ \\
& P3 & 52,8 & $84,2 \mathrm{a}$ \\
\hline
\end{tabular}

Em cada coluna, para cada fator, médias seguidas de mesma letra não diferem entre si, pelo teste de Tukey, a 5\% de probabilidade.

A análise estatística da altura de inserção da primeira espiga demonstrou que não houve alteração significativa dessa variável em função dos tratamentos propostos (Tabela 3). Esses resultados 
divergem dos obtidos por RAMOS (2001), que encontrou maior média na altura de inserção da primeira espiga em sementes colocadas a $3 ; 1$ e $7 \mathrm{~cm}$, na seqüência.

\section{CONCLUSÕES}

A profundidade de semeadura foi $o$ fator que mais influenciou na emergência e no desenvolvimento vegetativo da cultura do milho.

No segundo estádio, a semeadura mais profunda proporcionou menor altura das plantas.

A maior profundidade de semeadura não afetou significativamente a altura das plantas no estádio 4.

Nenhum dos fatores analisados influenciou na altura de inserção da primeira espiga e na altura das plantas.

\section{REFERÊNCIAS BIBLIOGRÁFICAS}

AMERICAN SOCIETY OF AGRICULTURAL ENGINEERS. ASAE standard: ASAE S477 terminology for soil-engaging components for conservation-tillage planters, drills and seeders. In: . Agricultural engineers yearbook of standards. St. Joseph, 1995. p.312-7.

BENINCASA, M.M.P. Análise de crescimento de plantas. Jaboticabal: FUNEP, 1988. 42 p.

COAN, R.M. Efeito da profundidade de semeadura e da compactação do solo sobre a semente no comportamento da aveia-preta (Avena strigosa, Schreb). 1996. 68 f. Monografia (Trabalho de Graduação em Agronomia) - Faculdade de Ciências Agrárias e Veterinárias, Universidade Estadual Paulista, Jaboticabal, 1996.

EMPRESA BRASILEIRA DE PESQUISA AGROPECUÁRIA. Centro Nacional de Pesquisa dos Solos. Sistema brasileiro de classificação dos solos. Brasília: 1999. 412 p.

FANCELLI, A.L.; DOURADO NETO, D. Ecofisiologia e fenologia. In: FANCELLI, A.L . (Ed.) Produção de milho. Guaíba: Agropecuária, 2000. 360 p.

FURLANI, C.E.A.; LOPES, A.; REZENDE, L.C.; SOUZA E SILVA, S.S; LEITE, M.A.S. Influência da compactação do solo na emergência das plântulas de milho a diferentes profundidades de semeadura. Engenharia na Agricultura, Viçosa, v.9, n.3, p.147-53, 2001.

HUMMEL, J.W.; GRAY, L.E.;NAVE, W.R. Soybean emergence from field seedbed environments. Transactions of the ASAE, St. Joseph, v.24, n.4, p.872-8, 1981.

JOHNSON, W.J.; BUCHELE, W.F. Influence of soil granule size and compaction on rate of soil drying and emergence of corn. Transactions of the ASAE, St. Joseph, v.4, n.2, p.170-4,1961.

JOHNSON, W.J.; HENRY, J.E. Influence of simulated row compaction on seedling emergence and soil drying rates. Transactions of the ASAE, St. Joseph, v.7, n.3, p.252-5,1964.

MONTEIRO, J.A.; CRUZ, J.C.; SANS, L.M.A.; BAHIA, F.G.T.C.; SANTANA, D.P.; GARCIA, J.C.; BAHIA FILHO, A.F.C. Produção de milho no Brasil: realidade e perspectiva. In: CONGRESSO NACIONAL DE MILHO E SORGO, 19., 1992, Porto Alegre. Conferências... Porto Alegre: SAA/SCT/ABMS/EMATER-RS/CNPMS-EMBRAPA/CIENTEC,1992. p.81-126.

ORTOLANI, A.F.; BANZATTO, D.A.; BORTOLI, N.M. Influência da profundidade de semeadura e da compactação do solo, na emergência e desenvolvimento do sorgo granífero (Sorghum bicolor (L.) MOENCH). In: CONGRESSO BRASILEIRO DE ENGENHARIA AGRÍCOLA, 15., 1986, São Paulo. Anais... Botucatu: Sociedade Brasileira de Engenharia Agrícola, 1986. p.27-39. 
PACHECO, E.P. Avaliação de uma semeadora-adubadora de precisão com modificações no tubo condutor de sementes. 1994. 61 f. Dissertação (Mestrado em Mecanização Agrícola) - Universidade Federal de Viçosa, Viçosa - MG, 1994.

RAMOS, N.P. Efeitos do tamanho de sementes de milho doce e comum (Zea mays L.) sobre seu desempenho vegetativo e produtivo, sob condições de estresse por profundidade de semeadura. 2001. 81 f. Dissertação (Mestrado em Produção e Tecnologia de Sementes) - Faculdade de Ciências Agrárias e Veterinárias, Universidade Estadual Paulista, Jaboticabal, 2001.

ROSOLEM, C.A. Relações solo-planta na cultura do milho. Jaboticabal: FUNEP, 1995. 53 p.

SILVA, F.M. Influência do tipo de rodas compactadoras de semeadoras-adubadoras no condicionamento físico do solo e no desenvolvimento de plantas. 1990. 131 f. Dissertação (Mestrado em Máquinas Agrícolas) - Universidade Estadual de Campinas, Campinas, 1990.

SIQUEIRA, R. Sistemas de preparo em diferentes tipos de coberturas vegetais do solo. 1999. $191 \mathrm{f}$. Tese (Doutorado em Energia na Agricultura). Faculdade de Ciências Agronômicas, Universidade Estadual Paulista, Botucatu, 1999.

STEFANUTTI, R. Desenvolvimento de uma pista de ensaio e carrinho com rodas compactadoras para estudos relacionados com emergência de plântulas. 1979. 60 f. Monografia (Trabalho de Graduação em Agronomia) - Faculdade de Ciências Agrárias e Veterinárias, Universidade Estadual Paulista, Jaboticabal, 1979.

TILMANN, M. A. A.; PIANA, Z.; CAVAIANI, C.; MINAMI, K. Efeito da profundidade de semeadura na emergência de plântulas de tomate (Lycopersicun esculentum Mill.). Scientia Agricola, Piracicaba, v.51, n.2, p.260-3, 1994.

VIÉGAS, G. P.; PEETEN, H. Sistemas de produção. In: PATERNIANI, E.; VIÉGAS, G. P. (Eds). Melhoramento e produção do milho. Campinas: Fundação Cargill, 1987. p.453-538. 